\title{
Needs for Medical and Rehabilitation Services in Adults With Cerebral Palsy in Korea
}

\author{
Myung Woo Park, MD', Won Sep Kim, MD', Moon Sulk Bang, MD, PhD ${ }^{1}$, Jae Young Lim, MD, PhD², \\ Hyung-Ik Shin, MD, $\mathrm{PhD}^{1}$, Ja-Ho Leigh, $\mathrm{MD}^{3}$, Keewon Kim, MD, $\mathrm{PhD}^{1}$, Bum Sun Kwon, $\mathrm{MD}$, $\mathrm{PhD}^{4}$, \\ Soong-Nang Jang, $\mathrm{PhD}^{5}$, Se Hee Jung, $\mathrm{MD}, \mathrm{PhD}^{6}$
}

\begin{abstract}
${ }^{1}$ Department of Rehabilitation Medicine, Seoul National University Hospital, Seoul; ${ }^{2}$ Department of Rehabilitation Medicine, Seoul National University Bundang Hospital, Seongnam; ${ }^{3}$ Department of Rehabilitation Medicine, Incheon St. Mary's Hospital, College of Medicine, The Catholic University of Korea, Incheon; ${ }^{4}$ Department of Rehabilitation Medicine, Dongguk University

College of Medicine, Goyang; ${ }^{5}$ Red Cross College of Nursing, Chung-Ang University, Seoul; ${ }^{6}$ Department of Rehabilitation Medicine, Seoul National University Boramae Medical Center, Seoul, Korea
\end{abstract}

\begin{abstract}
Objective To investigate medical comorbidities and needs for medical and rehabilitation services of adults with cerebral palsy (CP) in Korea.

Methods This was a prospective cross-sectional study. One hundred fifty-four adults with CP were enrolled in the study between February 2014 and December 2014. Information was obtained from participants regarding functional status, demographic and socioeconomic data, medical problems, and requirements for and utilization of medical and rehabilitation services.

Results The participants included 93 males and 61 females with a mean age of $40.18 \pm 9.15$ years. The medical check-up rate of adults with CP was lower than that of healthy adults and the total population with disabilities (53.2\% vs. $58.6 \%$ vs. $70.4 \%$ ). A quarter of the subjects failed to visit the hospital during the past year, and the main reason was the financial burden. Due to a cost burden and lack of knowledge, more than one-third of the subjects had unmet needs for rehabilitation services; the majority reported needs for rehabilitation services, such as physical therapy for pain management.

Conclusion The medical check-up rate was lower in the adults with CP, even though their medical comorbidities were not less than those of healthy people. Several non-medical reasons hindered them from receiving proper medical and rehabilitation services. Such barriers should be managed effectively.
\end{abstract}

Keywords Cerebral palsy, Rehabilitation, Medical, Adult, Comorbidity

Received June 2, 2017; Accepted September 6, 2017

Corresponding author: Se Hee Jung

Department of Rehabilitation Medicine, Seoul National University Boramae Medical Center, 20 Boramae-ro 5-gil, Dongjak-gu, Seoul 07061, Korea. Tel: +82-2-870-2672, Fax: +82-2-831-2826, E-mail: ideale1@snu.ac.kr

ORCID: Myung Woo Park (http://orcid.org/0000-0001-7531-8433); Won Sep Kim (http://orcid.org/0000-0000-1170-1545); Moon Suk Bang (http:// orcid.org/0000-0002-1093-6908); Jae Young Lim (http://orcid.org/0000-0002-9454-0344); Hyung-Ik Shin (http://orcid.org/0000-0001-8805-3104); JaHo Leigh (http://orcid.org/0000-0003-0465-6392); Keewon Kim (http://orcid.org/0000-0001-6597-578X); Bum Sun Kwon (http://orcid.org/0000-00017755-435X); Soong-Nang Jang (http://orcid.org/0000-0003-2621-945X); Se Hee Jung (http://orcid.org/0000-0002-0623-8752).

(c) This is an open-access article distributed under the terms of the Creative Commons Attribution Non-Commercial License (http://creativecommons.org/ licenses/by-nc/4.0) which permits unrestricted noncommercial use, distribution, and reproduction in any medium, provided the original work is properly cited. Copyright $\odot 2018$ by Korean Academy of Rehabilitation Medicine 


\section{INTRODUCTION}

Cerebral palsy (CP) describes a group of disorders leading to the development of abnormal movement and posture causing limitations in activity. These disorders are attributed to non-progressive disturbances that occur in the developing fetal or infant brain [1]. The movement disorders of $\mathrm{CP}$ are often associated with behavioral disabilities, seizures, and musculoskeletal involvement, as well as disturbances of sensation, perception, cognition, communication [1].

The prevalence of CP in the United States in 2006 was 3.3 per 1,000 [2]. According to one study that examined 5 -year-old children in South Korea, the prevalence of CP was 3.2 per 1,000 children in 2008 [3]. Most patients with $\mathrm{CP}$ reach adulthood due to the development of healthcare services, and very few deaths are attributed to $\mathrm{CP}$ among those dying over 20 years of age [4]. However, if children with CP reach adulthood, they may be faced with new medical and orthopedic problems. Murphy et al. [5] examined 101 adults with CP. Most of the patients lost their ability to walk by the age of 25 years, due to the high prevalence of musculoskeletal problems. The researchers suggested that the activity limitations and biomechanical forces led to excessive physical stress and degenerative change. Furthermore, Bottos et al. [6] examined 72 adults diagnosed with CP and reported that heavy use of the musculoskeletal system to perform activities of daily living may provoke early musculoskeletal problems.

In a manner similar to other childhood-onset disabilities and illnesses, attention to healthcare issues in patients with CP has usually focused on the issues in infancy and childhood. Many studies described the organized healthcare systems for these patients as poor and inadequate $[7,8]$. As a result, once the patient reached adulthood, contact with healthcare centers was dramatically reduced [8]. Accordingly, the attributable healthcare cost per person with $\mathrm{CP}$ was higher for older patients than for younger ones [3].

$\mathrm{CP}$ is a heterogeneous syndrome, and individuals with CP may need specialized medical care, educational and social services, and other assistance throughout their lives from their families and communities [5]. Thus, information regarding medical problems and the needs for medical and rehabilitation services are essential in order to provide effective healthcare services to adult patients with CP. However, little has been published regarding the general health, medical services, and requirements for rehabilitation, apart from the study regarding musculoskeletal problems of adults with $\mathrm{CP}$ in South Korea.

Taking these facts into account, we conducted this study on a population of adults with CP. The aims of the present study are (1) to investigate the prevalence and characteristics of medical comorbidities and (2) to describe the needs for medical and rehabilitation services of adults with $\mathrm{CP}$ in South Korea.

\section{MATERIALS AND METHODS}

\section{Subjects}

This was a prospective cross-sectional study. Patients diagnosed with $\mathrm{CP}$, aged 19 years or older, were recruited from the outpatient clinics of the rehabilitation department in several hospitals or organizations and federations of people with disabilities on a national scale. The patients who were diagnosed with other neurologic diseases that might cause significant disability, and patients who could not complete the questionnaire, were excluded. A total of 243 subjects were screened for eligibility between February 2014 and December 2014. Among them, 83 subjects were unwilling or unable to participate in the study, and in 6 patients, a CP diagnosis could not be confirmed. Finally, a total of 154 subjects provided informed consent and were enrolled into the study.

\section{Procedure}

The information gathered in this study was obtained using a structured questionnaire. The questionnaire contained questions about medical status, functional status, needs for medical and rehabilitation services, and actual utilization of medical and rehabilitation services. Furthermore, demographic and socioeconomic data were also acquired. In this study, mixed type of CP was defined as subjects with mixed spasticity, dystonia, and ataxia. Subjects completed and turned in the questionnaires at the two outpatient clinics, or they mailed the questionnaires through organizations or federations for persons with disabilities. The level of gross motor function was assessed based on the Gross Motor Function Classification System (GMFCS) criteria in patients 12-18 years old. Finally, we compared the results of this study with the results from a previous Nationwide Disability Survey 2011 
Table 1. Demographics of adults with cerebral palsy

\begin{tabular}{|c|c|}
\hline Characteristic & No. (\%) \\
\hline \multicolumn{2}{|l|}{ Age (yr) } \\
\hline 20-29 & $17(11)$ \\
\hline $30-39$ & $58(37.7)$ \\
\hline $40-49$ & $59(38.3)$ \\
\hline $50-59$ & $17(11)$ \\
\hline $60-69$ & $3(1.9)$ \\
\hline \multicolumn{2}{|l|}{ Sex } \\
\hline Male & $93(60.4)$ \\
\hline Female & $61(39.6)$ \\
\hline \multicolumn{2}{|l|}{ Occupied area } \\
\hline Seoul & $104(67.6)$ \\
\hline Incheon, Gyeonggi & $23(14.9)$ \\
\hline Busan, Gyeongam & $9(5.8)$ \\
\hline Daegu, Gyeongbuk & $7(4.5)$ \\
\hline Kangwon & $5(3.3)$ \\
\hline Gwangju, Jeonam & $5(3.3)$ \\
\hline Non-response & $1(0.6)$ \\
\hline \multicolumn{2}{|l|}{ Marriage } \\
\hline Unmarried & $107(69.5)$ \\
\hline Married & $31(20.1)$ \\
\hline Bereaved & $1(0.6$ \\
\hline Divorced & $12(7.8)$ \\
\hline Separated & $2(1.3)$ \\
\hline No-response & $1(0.6)$ \\
\hline \multicolumn{2}{|l|}{ Education } \\
\hline Uneducated & $22(14.3)$ \\
\hline Elementary school & $8(5.2)$ \\
\hline Middle school & $15(9.7)$ \\
\hline High school & $69(44.8)$ \\
\hline Technical college & $11(7.1)$ \\
\hline University & $25(16.2)$ \\
\hline Graduate school & $2(1.3)$ \\
\hline No-response & $2(1.3)$ \\
\hline \multicolumn{2}{|l|}{ Cerebral palsy type } \\
\hline \multicolumn{2}{|l|}{ Total abnormality } \\
\hline Spastic & $63(40.9)$ \\
\hline Dyskinetic & $32(20.8)$ \\
\hline Ataxic & $1(0.6)$ \\
\hline Mixed & $47(30.5)$ \\
\hline Do not know/No-response & $11(7.1)$ \\
\hline \multicolumn{2}{|l|}{ Topographic distribution } \\
\hline Quadriplegia & $93(60.4)$ \\
\hline Diplegia & $23(14.9)$ \\
\hline Hemiplegia & $23(14.9)$ \\
\hline Monoplegia & $4(2.6)$ \\
\hline No-response & $11(7.1)$ \\
\hline
\end{tabular}

Table 1. Continued

\begin{tabular}{|ll}
\hline \multicolumn{1}{c}{ Characteristic } & No. (\%) \\
\hline GMFCS level & \\
\hline I & $22(16.3)$ \\
II & $47(34.8)$ \\
III & $10(7.4)$ \\
IV & $46(34.1)$ \\
V & $10(7.4)$ \\
\hline
\end{tabular}

GMFCS, Gross Motor Function Classification System.

in South Korea.

\section{Statistical analysis}

The type of CP, GMFCS level, and other demographic and socioeconomic data were treated as independent variables. These were categorized into several groups in order to verify any differences. Dependent variables were medical comorbidities, medical check-up status, and utilization patterns of rehabilitation services. For statistical analysis, Pearson chi-square test was performed to find any significant differences among the groups. All tests were two-sided, and $\mathrm{p}<0.05$ was considered statistically significant. SPSS version 19.0 (IBM, Armonk, NY, USA) was used.

\section{RESULTS}

\section{Demographics}

A total of 154 patients were included in this study (Table 1). The study population included 93 males and $61 \mathrm{fe}-$ males with a mean age of $40.18 \pm 9.15$ years. Table 1 shows the types of $\mathrm{CP}$ and levels of gross motor function. The proportion of patients with spastic type and quadriplegic type CP was higher than any other type.

\section{Medical comorbidities}

Adults with CP were at an increased risk of immobility and fragility due to many musculoskeletal problems such as pain, spasticity, contracture, deformity, and degenerative arthritis. Moreover, as shown in Table 2, other medical comorbidities were common. The most common comorbidities were gastritis (11.7\%), hypertension (10.4\%), gastroesophageal reflux disease (9.1\%), hyperlipidemia (5.2\%), and diabetes mellitus (4.5\%). There was no statistically significant correlation between medical comorbidities and the type of CP or GMFCS levels. 
Table 2. Medical comorbidities in adults with cerebral palsy

\begin{tabular}{lccccc}
\hline & \multicolumn{5}{c}{ Comorbidity } \\
\cline { 2 - 6 } & $\mathbf{2 0 - 2 9} \mathbf{~ y r}$ & $\mathbf{3 0 - 3 9} \mathbf{~ y r}$ & $\mathbf{4 0 - 4 9} \mathbf{~ y r}$ & $\mathbf{5 0} \mathbf{~ y r}$ & Total \\
\hline Gastritis & 0 & 3 & 10 & 5 & $18(11.7)$ \\
Hypertension & 1 & 2 & 9 & 4 & $16(10.4)$ \\
\hline GERD & 2 & 2 & 8 & 2 & $14(9.1)$ \\
Hyperlipidemia & 0 & 5 & 3 & 0 & $8(5.2)$ \\
DM & 1 & 5 & 0 & 1 & $7(4.5)$ \\
Epilepsy & 2 & 2 & 1 & 0 & $5(3.2)$ \\
Others & 0 & 9 & 7 & 3 & $19(12.3)$ \\
\hline
\end{tabular}

Values are presented as number (\%).

GERD, gastroesophageal reflux disease; DM, diabetes mellitus.

\section{Needs for medical service}

The healthcare status of adults with CP is presented in Table 3. In total, $53.2 \%$ of the patients received a medical check-up in the past 2 years, while $44.2 \%$ did not.

Over half $(53.9 \%)$ of the subjects visited a hospital to receive routine medical or rehabilitation check-ups more than once a year. Subjects with GMFCS level IV and V $(p=0.05)$, women $(p=0.04)$, recipients of the National Basic Livelihood Security ( $p=0.002$ ), and Medical Aid recipients $(\mathrm{p}=0.005)$ reported a hospital visit more frequently than the others. When subjects were classified according to their GMFCS level, ambulatory subjects with GMFCS I, II, and III did not show any statistically significant differences in medical follow-up based on sex and the receipt of National Basic Livelihood Security or Medical Aid. However, more frequent periodic medical follow-ups were reported by non-ambulatory subjects with GMFCS IV and V, women ( $\mathrm{p}=0.01)$, and recipients of the National Basic Livelihood Security ( $\mathrm{p}=0.05)$. The purposes of the hospital visits were medical treatment (47.8\%), rehabilitation (36.7\%), and healthcare or prevention (12.2\%).

Among subjects who were not visiting hospitals routinely, $40.6 \%$ reported that this was because they did not need a routine check-up, whereas $27.3 \%$ reported financial causes, $13.3 \%$ reported a lack of time, and $9.1 \%$ reported difficulty in visiting a hospital.

Some subjects (24.7\%) failed to visit the hospital during the past year, and they attributed this to financial problems (47.4\%), inconvenience in transportation (15.8\%), long waiting times $(7.7 \%)$, difficulty in making appointments (5.3\%), and difficulty in arriving at the hospital on time (5.3\%).

\section{Needs for rehabilitation service}

Table 4 shows the usage and needs for rehabilitation services. About a third of subjects $(37.0 \%)$ were receiving rehabilitation therapy. Women $(\mathrm{p}=0.002)$, recipients of the National Basic Livelihood Security $(\mathrm{p}=0.002)$, and Medical Aid recipients $(\mathrm{p}=0.003)$ received rehabilitation services more frequently than did others. When comparing the frequencies of utilization of rehabilitation services, non-ambulatory subjects (GMFCS level IV and V) tended to utilize rehabilitation services more frequently than ambulatory subjects (GMFCS level I, II, and III; $\mathrm{p}=0.09$ ). In addition, the non-ambulatory subjects, women $(p=0.05)$, recipients of the National Basic Livelihood Security ( $\mathrm{p}=0.03)$, and Medical Aid recipients $(\mathrm{p}=0.04)$ received rehabilitation treatment more frequently. However, there were no significant differences in the utilization of rehabilitation services except in terms of the sex in the ambulatory patients. In this category, women received more rehabilitation services than men $(\mathrm{p}=0.02)$. Among subjects who were receiving rehabilitation therapy, $91.3 \%$ received physical therapy, and $26.2 \%$ received occupational therapy. Of the subjects who were not receiving rehabilitation therapy, $43.0 \%$ reported that they had no need, $23.2 \%$ reported that it was a financial burden, and $7.0 \%$ reported a lack of knowledge.

Adults with $\mathrm{CP}$ reported the most needed services were pain treatment (42.9\%), physical therapy (35.7\%), examination by a physiatrist (27.3\%), orthosis prescriptions (14.3\%), occupational therapy (11\%), and surgery (3.9\%). Regarding present and future device utilization, $41.6 \%$ reported electric wheelchair or scooter, $18.2 \%$ reported posture maintenance aids, $9.1 \%$ reported communication aids, $7.8 \%$ reported telecommunication aids, $5.8 \%$ 
Table 3. Utilization of healthcare service

\begin{tabular}{|c|c|c|}
\hline \multicolumn{2}{|c|}{ 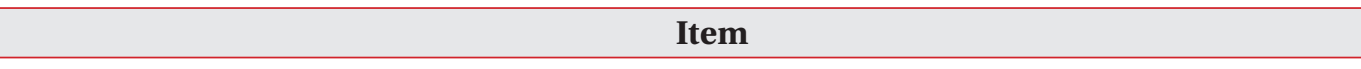 } & Response rate (\%) \\
\hline \\
\hline \multirow[t]{6}{*}{ Yes } & Type of medical check-ups & 53.2 \\
\hline & - Private health screening & 9.46 \\
\hline & - Workplace health checks & 4.82 \\
\hline & - Medical check-ups provided by national health insurance services & 45.83 \\
\hline & - Free medical check-ups & 42.1 \\
\hline & - Others & 3.5 \\
\hline No & & 44.2 \\
\hline No-response & & 2.6 \\
\hline \multicolumn{3}{|c|}{ Regular hospital visits more than once a year } \\
\hline \multirow[t]{8}{*}{ Yes } & Type of medical facility & 53.9 \\
\hline & - General hospital & 52.4 \\
\hline & - Private clinic & 22.6 \\
\hline & - Rehabilitation hospital & 19.1 \\
\hline & - Disabled people health facility & 5.9 \\
\hline & - Oriental medicine hospital clinic & 4.8 \\
\hline & - Regional health center & 2.4 \\
\hline & - Others & 1.1 \\
\hline \multirow[t]{7}{*}{ No } & Reasons for no hospital visit & 42.9 \\
\hline & - No personal necessity & 40.6 \\
\hline & - Financial burden & 27.3 \\
\hline & - Lack of time & 13.3 \\
\hline & - Difficult to visit hospital & 9.1 \\
\hline & - Do not want to visit hospital & 4.2 \\
\hline & - Others & 4.2 \\
\hline No-response & & 3.2 \\
\hline \multicolumn{3}{|c|}{ Have you failed to visit the hospital during the past 1 year? } \\
\hline \multirow[t]{7}{*}{ Yes } & Reasons for failing to visit the hospital & 24.7 \\
\hline & - Financial burden & 47.4 \\
\hline & - Inconvenience in transportation & 15.8 \\
\hline & - Long waiting list & 7.7 \\
\hline & - Difficulty in making appointments & 5.3 \\
\hline & - Difficulty in arriving at the hospital on time & 5.3 \\
\hline & - Others & 21.1 \\
\hline No & & 70.8 \\
\hline No-response & & 4.5 \\
\hline
\end{tabular}

reported manual wheelchair, and $2.6 \%$ reported gait aids.

\section{DISCUSSION}

Information regarding the medical problems of adults with CP is essential, and the necessity for medical and rehabilitation services should be met to manage these health issues effectively. Therefore, this study focused on the prevalence of medical comorbidities and the usage and needs of medical and rehabilitation services for adults with CP. The prevalence of CP has increased as a result of improvement in medical intervention for prema- 
Table 4. Rehabilitation services - needed and offered

\begin{tabular}{|c|c|c|}
\hline & Item & Response \\
\hline Are y & urrently receiving rehabilitation & rapy? \\
\hline Yes & $\begin{array}{l}\text { Rehabilitation therapy received } \\
\text { (multiple choice) }\end{array}$ & $57(37.0)$ \\
\hline & - Physical therapy & $52(91.3)$ \\
\hline & - Occupational therapy & $15(26.2)$ \\
\hline & - Speech therapy & $2(3.5)$ \\
\hline & - Art therapy & $2(3.5)$ \\
\hline & - Behavioral psychotherapy & $2(3.5)$ \\
\hline & - Music therapy & $1(1.6)$ \\
\hline & - Play therapy & $1(1.6)$ \\
\hline & - Others & $6(10.5)$ \\
\hline No & Reasons for no hospital visit & $92(59.7)$ \\
\hline & - No need & $37(43.0)$ \\
\hline & - Financial burden & $20(23.2)$ \\
\hline & - Lack of knowledge & $6(7.0)$ \\
\hline & - No facilities & $4(4.7)$ \\
\hline & - On the waiting list & $4(4.7)$ \\
\hline & - No reliable services & $3(3.5)$ \\
\hline & - Other services available & $1(1.2)$ \\
\hline & - Others & $11(12.7)$ \\
\hline No & ponse & $5(3.2)$ \\
\hline
\end{tabular}

Values are presented as number (\%).

ture births. Most patients with CP reach adulthood because very few deaths were attributed to $\mathrm{CP}$ for those dying over 20 years of age [3]. However, medical resources have been focused mainly on the problems of CP patients during infancy and childhood; thus, there must be some unmet needs for medical and rehabilitation treatments for adults with CP. However, there have been no reports on the medical comorbidities and necessities for medical and rehabilitation services in adults with CP in Korea. The National Survey on Persons with Disabilities in 2011 reported that hypertension (33.5\%) was the most common medical problem in the entire population with disabilities; however, this study found that gastritis (11.7\%), hypertension (10.4\%), and gastroesophageal reflux disease $(9.1 \%)$ occurred most frequently. Additionally, we found that the medical check-up rate of adults with $\mathrm{CP}$ was $53.2 \%$, which was similar to or lower than that of non-disabled adults (58.6\%), and much lower than that of the entire population with disabilities $(70.4 \%)[9,10]$. These figures are not significantly different from the re- sults of other surveys completed in 2011, which indicated that the regular medical check-up rate among those with $\mathrm{CP}$ was $50 \%$. The difference in the medical check-up rate between the two groups might be due to the burden of expenses, inconvenience in transportation, or a lack of awareness regarding the importance of a regular medical check-up. Although $45.5 \%$ of the subjects in our study had a job, most of them were employees of organizations for people with disabilities, which do not provide a workplace health check-up service. This may be one reason for the differences in the medical check-up rate.

Since CP patients might have higher incidences of medical and orthopedic problems as they age, it is important that adults with CP visit the hospital regularly to check their medical condition [5]. However, there might be unmet needs for medical services because of the traditional childhood-oriented approach. Bax et al. [7] reported a study of 104 young people with physical handicaps that assessed their state of health and determined whether their health needs were met. Among them, 45 had cerebral palsy, and their state of health was generally poor. Over half of the participants had health problems that were severe enough to warrant intervention, but less than a third were receiving regular hospital care. In this study, we found that because of the burden of expenses and difficulty of transportation, $42.9 \%$ did not visit the hospital for a regular follow-up. In addition, $24.7 \%$ had failed to visit the hospital during the past year, even though they felt that it was required. Financial burden was given as the main reason for this failure. This is similar to the results of the 2011 survey, which stated that the most common reason for the lack of a hospital visit was the burden of expenses. Additionally, considering that the purpose of visiting the hospital was mostly for treatment rather than for general healthcare or prevention, educating adults with $\mathrm{CP}$ about the importance of a regular medical follow-up is required. This study also found that patients whose GMFCS levels were IV and V visited the hospital to receive routine medical or rehabilitation examinations for healthcare more regularly than subjects whose GMFCS levels were I, II, and III because they might require more frequent medical and rehabilitation services. Medical aid recipients and recipients of the National Basic Livelihood Security also received medical care more routinely than others. The government supports these people, and this may improve hospital accessibility. Thus, 
visiting the hospital could be a burden for subjects who do not receive medical aid.

About $59.7 \%$ of patients did not receive rehabilitation treatment at all (Table 4). Only half of the subjects who did not receive rehabilitation therapy reported that they did not require treatment. In other words, the other half were not offered adequate rehabilitation services and had unmet needs for rehabilitation treatment. The main reasons for not seeking these services were cost burden and lack of knowledge. For this reason, recipients of the National Basic Livelihood Security and Medical Aid recipients may receive rehabilitation therapies more frequently than others who did not receive Medical Aid from government. Others reported the lack of facilities or long waiting lists as the reasons for not receiving rehabilitation therapies. Andersson and Mattsson [11] reported that $49 \%$ of adults with CP living in the County of Stockholm did not receive physiotherapy at all, and many of them experienced difficulty in finding a physiotherapist who had time and were interested in seeing adult CP patients. Differences of healthcare policies between the two countries contributed to these findings.

Adults with CP may have a higher incidence of secondary musculoskeletal and medical problems, such as muscle weakness, spasticity, contracture, deformity, and degenerative arthritis [3]. Thus, regular physical therapy, education, and adequate pain treatment should be provided to them. Actually, in the present study, the majority of adults with CP reported the need for at least one rehabilitation service. For example, $42.9 \%$ of the responders reported a need for pain treatment, $35.7 \%$ answered that they wanted to receive physical therapy, and $27.3 \%$ reported a need for an examination by a rehabilitation medicine specialist. In order to prevent secondary complications in adults with $\mathrm{CP}$, these findings must be considered by the health authorities in the future planning of rehabilitation services. As expected, non-ambulatory adults were more likely to report the need for physical therapy than ambulatory ones. Since these patients are more likely to experience medical complications, regular hospital care must be provided to them.

Our study is meaningful, since it is the first study to investigate the medical status and needs for medical and rehabilitation services of adults with CP. However, there were several limitations. First, the study population was not a random sample. We tried to enroll adults with $\mathrm{CP}$ nationwide, but the distance may have hindered some subjects from participating in the study. Moreover, the severity or type of CP was not evenly distributed. Second, the information regarding rehabilitation and medical services was based only on the subjects' reports. Detailed information on the type, dose, and intensity of physical therapy could not be gathered. There is a possibility that the medical diagnoses were not fully accurate, since most of the medical information was also self-reported. However, errors associated with the self-reported data are considered acceptable due to the relatively broad categories of questions being asked. Finally, our study used the GMFCS descriptive criteria from the upper age band (12-18 years), as there is no description for adults. However, several studies suggested that this age band can reliably be used to classify adults with CP. Jahnset et al. [12] suggested that the GMFCS can be a reliable classification tool for adults with $\mathrm{CP}$ and the inter-rater reliability between the self-reported and professional ratings is good. In addition, Sandstrom et al. [13] reported that the GMFCS is a useful instrument, especially for comparison throughout the life span of adults with CP. Future studies considering these factors may provide some interesting outcomes on CP patients' tendencies or situations in medical services usage.

In conclusion, the medical check-up rate of adults with CP was lower than that of the healthy population and other people with disabilities, even though their medical comorbidities were not less than those of healthy people. Although most subjects required medical and rehabilitation treatments, their needs were frequently unmet. Several non-medical reasons, such as financial burden or a lack of knowledge, hindered these patients from receiving proper medical and rehabilitation services. The results of such barriers are a general deterioration of the quality of life of adults with CP. For this reason, the treatment for adults with CP should be based on their entire life rather than only the childhood-oriented approach. Further follow-up studies should focus on establishing comprehensive practice guidelines for managing adults with $\mathrm{CP}$, and financial and technical resources for these patients need to be invested into the healthcare system.

\section{CONFLICT OF INTEREST}

No potential conflict of interest relevant to this article 
was reported.

\section{ACKNOWLEDGMENTS}

This research was supported by the R\&D grant of rehabilitation services by Korea National Rehabilitation Center Research Institute, Ministry of Health \& Welfare.

\section{REFERENCES}

1. Rosenbaum P, Paneth N, Leviton A, Goldstein M, Bax M, Damiano D, et al. A report: the definition and classification of cerebral palsy April 2006. Dev Med Child Neurol Suppl 2007;109:8-14.

2. Kirby RS, Wingate MS, Van Naarden Braun K, Doernberg NS, Arneson CL, Benedict RE, et al. Prevalence and functioning of children with cerebral palsy in four areas of the United States in 2006: a report from the Autism and Developmental Disabilities Monitoring Network. Res Dev Disabil 2011;32:462-9.

3. Park MS, Kim SJ, Chung CY, Kwon DG, Choi IH, Lee KM. Prevalence and lifetime healthcare cost of cerebral palsy in South Korea. Health Policy 2011;100:2348.

4. Hemming K, Hutton JL, Pharoah PO. Long-term survival for a cohort of adults with cerebral palsy. Dev Med Child Neurol 2006;48:90-5.

5. Murphy KP, Molnar GE, Lankasky K. Medical and functional status of adults with cerebral palsy. Dev Med Child Neurol 1995;37:1075-84.

6. Bottos M, Feliciangeli A, Sciuto L, Gericke C, Vianello
A. Functional status of adults with cerebral palsy and implications for treatment of children. Dev Med Child Neurol 2001;43:516-28.

7. Bax MC, Smyth DP, Thomas AP. Health care of physically handicapped young adults. Br Med J (Clin Res Ed) 1988;296:1153-5.

8. Thomas A, Bax M, Coombers K, Goldson E, Smyth D, Whitmore $\mathrm{K}$. The health and social needs of young adults with physical disabilities. London: Mac Keith Press; 1989. p. 60-9.

9. Ministry of Health and Welfare; Korea Centers for Disease Control and Prevention. Korea Health Statistics 2014: Korea National Health and Nutrition Examination Survey (KNHANES VI-2). Sejong: Ministry of Health and Welfare; 2015.

10. Kim SH, Byun YC, Son CG, Lee YH, Lee MK, Lee SH, et al. 2011 National survey on persons with disabilities. Sejong: Ministry of Health and Welfare; 2011.

11. Andersson C, Mattsson E. Adults with cerebral palsy: a survey describing problems, needs, and resources, with special emphasis on locomotion. Dev Med Child Neurol 2001;43:76-82.

12. Jahnsen R, Aamodt G, Rosenbaum P. Gross Motor Function Classification System used in adults with cerebral palsy: agreement of self-reported versus professional rating. Dev Med Child Neurol 2006;48:734-8.

13. Sandstrom K, Alinder J, Oberg B. Descriptions of functioning and health and relations to a gross motor classification in adults with cerebral palsy. Disabil Rehabil 2004;26:1023-31. 